\title{
Double-faced Estrogen
}

\section{Hui Li*}

Department of Pathology, University of Virginia, Charlottesville, VA, USA

A wealth of evidence indicates that steroid hormone estrogens contribute to the tumorigenesis of many cancer types [1-5]. They can promote cell proliferation and stimulate cell division, while also cause random errors during DNA replication [6-10].

However, back in 1940s, the first chemotherapy agent for breast cancer was high dose of synthetic estrogen DES (diethylstilbestrol) [11]. DES was also used to treat metastatic prostate cancer. Exact mechanism of the cancer suppressive effect of estrogens is not known, but about $30 \%$ patients responded to the treatment. In 1970s, tamoxifen was developed [12]. After the publication of the landmark study by Mayo Clinic comparing the effect of tamoxifen with DES showing that far fewer adverse effect was seen in tamoxifen-treated group [13], tamoxifen became the "gold standard" for treating ER-positive breast cancer. The practice of using DES to treat prostate cancer was also mostly replaced with the introduction of leuprolide in 1985 . The fact that estrogens have been used therapeutically to treat cancer is unknown to most clinicians trained in the era of tamoxifen and other anti-estrogen drugs.

Interestingly, several recent studies now signal a potential comeback of estrogens as cancer treatment or prevention agents. The long-term follow-up of the Mayo Clinic study showed significantly improved survival with patients treated with DES [14]. In addition, the analysis of estrogen replacement therapy in the Women's Health Initiative (WHI) double-blind, placebo-controlled randomized trial in 10,739 postmenopausal women showed a decrease risk for invasive breast cancer [15]. The authors concluded that exogenous estrogens are protective, but endogenous estrogens are carcinogenic (Cancer Res 2009;69(24 Suppl):Abstract nr 908). In 2001, the clinical benefit of using high dose DES treating metastatic breast cancer which are resistant to anti-hormone therapies. Complete or partial response was seen in onethird of the patients.

Where does the anti-tumor effect of estrogens come from? Studies have shown that high concentration estrogens can induce apoptosis through FAS/FASL pathway [16]. Ellis et al. [17] found that $6 \mathrm{mg}$ daily dose of estrogen is as effective as $30 \mathrm{mg}$ daily on metastatic cancer and the low dose had fewer side effects. The idea is that cells survive the long-term estrogen deprivation become sensitive to re-exposure of estrogen even at physiological dose [18].

The estrogens can undergo extensive oxidative metabolism, which produce mostly 2-hydroxyestrone/estradiol, and 4-hydroxyestrone/ estradiol. Catecholestrogens have been reported as potential carcinogens and induce DNA mutations by evidence of loss of heterozygosity in cultured cells [19]. However, 2-hydroxyestraiol seems to be less of a carcinogen since 500-fold more concentrated 2-hydroxyestradiol is needed to trigger DNA mutation than 4-hydroxyestradiol or estradiol itself. The catecholestrogens can be further metabolized by catechol-O-methyltransferase (COMT) into methoxyestrogens [20]. Methoxyestrogens, especially 2-methoxyestrogens have potent tumorsuppressive effects both in vitro [21-23], and in vivo. 2-methoxyestrogens have been reported to disrupt microtubule dynamics by destabilizing the tubulin polymers [23]. Several phase II clinical trials have been completed with $2 \mathrm{ME} 2$ showing some promise in suppressive several types of cancer. Whether some of the anti-tumor effect is mediated by estrogen metabolites is interesting, yet unexplored.

\section{References}

1. Chlebowski RT, Schwartz AG, Wakelee H, Anderson GL, Stefanick ML, et al. (2009) Oestrogen plus progestin and lung cancer in postmenopausal women (Women's Health Initiative trial): a post-hoc analysis of a randomised controlled trial. Lancet 374: 1243-1251.

2. Garcia-Leiva J, Gamboa-Dominguez A, Ceron-Lizarraga T, Morales-Espinosa D, Meza-Junco J, et al. (2006) Response of negative estrogen-receptor hepatocarcinoma to tamoxifen, and survival of non-resectable patients. Ann Hepatol 5: 263-267.

3. Gelmann EP (1997) Tamoxifen for the treatment of malignancies other than breast and endometrial carcinoma. Semin Oncol 24: S1-65-S61-70.

4. Pike MC, Spicer DV, Dahmoush L, Press MF (1993) Estrogens, progestogens, normal breast cell proliferation, and breast cancer risk. Epidemiol Rev 15: 17-35.

5. Swain SM (2001) Tamoxifen for patients with estrogen receptor-negative breast cancer. J Clin Oncol 19: 93S-97S.

6. Bolton JL, Thatcher GR (2008) Potential mechanisms of estrogen quinone carcinogenesis. Chem Res Toxicol 21: 93-101.

7. Hecht JL, Mutter GL (2006) Molecular and pathologic aspects of endometrial carcinogenesis. J Clin Oncol 24: 4783-4791.

8. Henderson BE, Feigelson HS (2000) Hormonal carcinogenesis. Carcinogenesis 21: 427-433

9. Hevir N, Sinkovec J, Rizner TL (2011) Disturbed expression of phase I and phase II estrogen-metabolizing enzymes in endometrial cancer: lower levels of CYP1B1 and increased expression of S-COMT. Mol Cell Endocrinol 331: 158-167.

10. Zhu BT, Conney AH (1998) Functional role of estrogen metabolism in target cells: review and perspectives. Carcinogenesis 19: 1-27.

11. Haddow A, Watkinson JM, Paterson E, Koller PC (1944) Influence of Synthetic Oestrogens on Advanced Malignant Disease. Br Med J 2: 393-398.

12. Lerner LJ, Jordan VC (1990) Development of antiestrogens and their use in breast cancer: eighth Cain memorial award lecture. Cancer Res 50: 4177-4189.

13. Ingle JN, Ahmann DL, Green SJ, Edmonson JH, Bisel HF, et al. (1981) Randomized clinical trial of diethylstilbestrol versus tamoxifen in postmenopausal women with advanced breast cancer. N Engl J Med 304: 16-21.

14. Peethambaram PP, Ingle JN, Suman VJ, Hartmann LC, Loprinzi CL (1999) Randomized trial of diethylstilbestrol vs. tamoxifen in postmenopausal women with metastatic breast cancer. An updated analysis. Breast Cancer Res Treat 54: 117-122.

15. LaCroix AZ, Chlebowski RT, Manson JE, Aragaki AK, Johnson KC, et al (2011) Health outcomes after stopping conjugated equine estrogens among postmenopausal women with prior hysterectomy: a randomized controlled trial. JAMA 305: 1305-1314.

*Corresponding author: Hui Li, Assistant Professor of Pathology in the Cance Center, Department of Pathology, Carter Harrison Bldg (MR6), Rm B524, 345 Crispell Dr., University of Virginia, Charlottesville, VA 22908, USA, Tel: 434-9826680; E-mail: hui.li@virginia.edu; HI9r@virginia.edu

Received November 07, 2013; Accepted November 12, 2013; Published November 18, 2013

Citation: Li H (2013) Double-faced Estrogen. J Biomol Res Ther 2: e120. doi: 10.4172/2167-7956.1000e120

Copyright: (C) $2013 \mathrm{Li} \mathrm{H}$. This is an open-access article distributed under the terms of the Creative Commons Attribution License, which permits unrestricted use, distribution, and reproduction in any medium, provided the original author and source are credited. 
16. Song RX, Mor G, Naftolin F, McPherson RA, Song J, et al. (2001) Effect of long-term estrogen deprivation on apoptotic responses of breast cancer cells to 17beta-estradiol. J Natl Cancer Inst 93: 1714-1723.

17. Ellis MJ, Gao F, Dehdashti F, Jeffe DB, Marcom PK, et al. (2009) Lower-dose vs high-dose oral estradiol therapy of hormone receptor-positive, aromatase inhibitor-resistant advanced breast cancer: a phase 2 randomized study. JAMA 302: 774-780.

18. Jordan VC, Ford LG (2011) Paradoxical clinical effect of estrogen on breast cancer risk: a "new" biology of estrogen-induced apoptosis. Cancer Prev Res (Phila) 4: 633-637

19. Russo J, Hasan Lareef M, Balogh G, Guo S, Russo IH (2003) Estrogen and its metabolites are carcinogenic agents in human breast epithelial cells. J Steroid Biochem Mol Biol 87: 1-25.
20. Cavalieri E, Chakravarti D, Guttenplan J, Hart E, Ingle J, et al (2006) Catecho estrogen quinones as initiators of breast and other human cancers: implications for biomarkers of susceptibility and cancer prevention. Biochim Biophys Acta 1766: 63-78.

21. Zhu BT, Liehr JG (1996) Inhibition of catechol O-methyltransferase-catalyzed O-methylation of 2- and 4-hydroxyestradiol by quercetin. Possible role in estradiol-induced tumorigenesis. J Biol Chem 271: 1357-1363.

22. Mannisto PT, Kaakkola S (1999) Catechol-O-methyltransferase (COMT) biochemistry, molecular biology, pharmacology, and clinical efficacy of the new selective COMT inhibitors. Pharmacol Rev 51: 593-628.

23. Mabjeesh NJ, Escuin D, LaVallee TM, Pribluda VS, Swartz GM, et al. (2003) $2 \mathrm{ME} 2$ inhibits tumor growth and angiogenesis by disrupting microtubules and dysregulating HIF. Cancer Cell 3: 363-375. 